\title{
Visual acuity, amplitude of accommodation and near point of convergence and academic achievement in primary school learners in Bloemfontein*
}

\author{
Marsha Oberholzer ${ }^{\dagger}$, Mariette Nel ${ }^{\dagger \dagger}$, Stephen Hartley ${ }^{\dagger+\dagger}$, Melissa Maartens ${ }^{\dagger \dagger}$, Carla Pheiffer ${ }^{\dagger \dagger \dagger}$, \\ Monwabisi Nonkula ${ }^{\dagger \dagger \dagger}$ and Anel Steyn ${ }^{\dagger \dagger \dagger}$
}

${ }^{\dagger}$ 'tl'Department of Optometry, PO Box 339, School for Allied Health Professions, Faculty of Health Sciences, University of the Free State, Bloemfontein, 9300

${ }^{\dagger}$ Department of Biostatistics, Faculty of Health Sciences, University of the Free State, Bloemfontein 9300

${ }^{\dagger}<$ oberholzerm@ufs.ac.za $>$

Received 20 November 2013; revised paper accepted 17 March 2014

\section{Abstract}

Introduction: Learning problems influencing the social and psychological development of children may result from poor visual acuity (VA), insufficient amplitude of accommodation and receded near point of convergence (NPC). This study assessed Grade 4 and 5 academic achievement $(<50 \%, 51-69 \%$ and $\geq 70 \%)$ in relation to visual acuity, amplitude of accommodation and NPC. The study attempts to determine the association between these visual functions and academic performance.

Methods: A cross-sectional study included a randomised sample of learners $(n=199)$ selected from five public schools in Bloemfontein. Information was obtained on each participant regarding history, visual acuity (distance and near), amplitude of accommodation and NPC (subjective and objective). Participant aggregates for the most recent school term and the grade average were compared to measures of these visual functions.

Results: The children's median age was 10.3 years (with range 8.7 to 12.7 years) and $53.8 \%$ were female. More than $50 \%$ of children were Sesotho-speaking. Complaints revealed by his- tory-taking were mostly headaches $(57.8 \%)$ and eyestrain $(58.3 \%)$. Regarding academic achievement, $18.6 \%$ of the learners were below average, $53.8 \%$ on average and $27.6 \%$ above average. Of the learners tested, $42.2 \%$ achieved a VA of $6 / 6$ or better on both distance and near visual acuity. Amplitude of accommodation was less than the minimum requirements in $17.6 \%$ of participants. Approximately $30 \%$ of those below grade average did not meet the minimum requirements for amplitude of accommodation, compared to $13 \%$ of learners above grade average, which was statistically significant. More than $70 \%$ had a receded break point ( $>5 \mathrm{~cm}$ ) for NPC and $85.7 \%$ had a receded recovery point $(>7 \mathrm{~cm})$.

Conclusion: Of the three visual functions evaluated in this study, the only visual function associated with academic achievement was amplitude of accommodation. It would thus be recommended that learners are screened for optimal visual function earlier in life if especially the amplitude of accommodation is receded. ( $S$ Afr Optom 2013 73(1) 33-38)

Key Words: Visual acuity in children, academic achievement and vision, amplitude of accommodation, near point of convergence 


\section{Introduction}

Learning problems that develop as a result of poor visual acuity, insufficient amplitude of accommodation and receded near point of convergence (NPC) play a vital role in the social, psychological and academic development of learners ${ }^{1-3}$. Academic performance at primary school level can affect not only self-esteem but may also contribute to substantial levels of stress experienced by children and parents. At secondary school level, academic performance is the primary requirement that determines acceptance into tertiary education, which may ultimately affect the individual's socio-economic status and well-being later in life.

Previous studies ${ }^{2,4}$ on children (learners) found that visual functions (visual acuity, muscle balance, preferred eye and hand, colour vision, refraction, sensory and motor function, and a writing and drawing task) and academic performance were possibly not positively related. A possible explanation for this observation could be that learners in the age group (Grade 1 to 3) have not yet been exposed to formal examinations, which require more extensive studying and reading, causing increased strain on the visual system. In Grades 4 and 5, children start to write formal examinations requiring them to study larger amounts of work for longer periods of time. The results of these examinations would be more representative of true academic performance.

A positive correlation was found between poor reading skills and reduced amplitude of accommodation, indicating the need for assessment of the accommodative function in learners who have reading difficulties ${ }^{5}$. Reading ability may have a direct effect on academic performance, and therefore assessment of the correlation between academic performance and amplitude of acuity is recommended.

Sterner et al. ${ }^{6}$ investigated the correlation between subjective symptoms when doing near work and the accommodative system. These authors ${ }^{6}$ found that symptoms, which included headache, eyestrain, floating text and flexibility problems, only started presenting between seven and eight years of age (typically Grade 2), somewhat justifying the decision to conduct our study on Grade 4 and 5 learners (age 9 - 11 years). Ideally, learning problems and possible related symptoms should be addressed at an early age.
Only a few studies found in the literature were done in South Africa and thus the aim of this study was to assess Grade 4 and 5 academic achievement $(<50 \%, 51-69 \%$ and $\geq 70 \%)$ in terms of amplitude of accommodation and NPC, to study the possible relationships between these visual functions and academic performance.

\section{Methods}

Approval to conduct the research was obtained from the Ethics Committee of the Faculty of Health Sciences, University of the Free State. The provincial Department of Education, learners' parent(s) or guardian(s), school principals and class teachers provided written consent for the 225 learners to participate in the study and to access their scholastic information. Participants assented to be included in the study. Consent and information documents were available in Afrikaans, English and Sesotho. Confidentiality was ensured for all participants included in the study and participants were allowed to withdraw at any stage during the study. Where the need for further visual assessment was indicated, learners were recommended to seek further eye care from an optometrist.

An observational, cross-sectional, descriptive study was conducted. The target population was public primary school learners in Grades 4 and 5 in Bloemfontein, Motheo District, Free State Province. These grades are regarded as typical where learners start writing formal examinations and where learning problems may become apparent. The Motheo District has 52 public primary schools. From the schools that could be contacted, only five schools were willing to participate in the study. Class lists from these five schools were ordered alphabetically per grade per school and each child was numbered. A proportional sample of learners per school was determined and study participants were then identified by means of a randomisation list obtained from a biostatistician. From a total of 225 learners selected from the five primary schools in Bloemfontein, 199 children participated in the study. (The mean number of learners per school was 45 , while the mean number of participants eventually included in the study was 39.8 per school.) 
Table 1. Number and percentage of Grades 4 and 5 learners selected from five primary schools in Bloemfontein.

\begin{tabular}{|c|c|c|c|c|c|}
\hline \multirow{2}{*}{ Primary schools } & \multicolumn{2}{|c|}{$\begin{array}{c}\text { Number of learners } \\
\text { per grade }\end{array}$} & \multirow{2}{*}{$\begin{array}{l}\text { Total per } \\
\text { school }\end{array}$} & \multirow{2}{*}{$\begin{array}{l}\text { Number of } \\
\text { learners per } \\
\text { school se- } \\
\text { lected }\end{array}$} & \multirow{2}{*}{$\%$ of tota } \\
\hline & Grade 4 & Grade 5 & & & \\
\hline School 1 & 160 & 160 & 320 & 58 & 18.1 \\
\hline School 2 & 113 & 112 & 225 & 41 & 18.2 \\
\hline School 3 & 166 & 154 & 320 & 58 & 18.1 \\
\hline School 4 & 49 & 50 & 99 & 18 & 18.2 \\
\hline School 5 & 139 & 140 & 279 & 50 & 17.9 \\
\hline Total & 627 & 616 & 1243 & 225 & 18.1 \\
\hline Mean per school & 125.4 & 123.2 & 248.6 & 45 & 18.1 \\
\hline
\end{tabular}

With regard to academic achievement, our sample included learners who performed on the total spectrum of poor to excellent. Twenty six learners with compensated refractive error wearing spectacles or contact lenses were excluded from the study to ensure a uniform emmetropic sample of participants included in the study. These 26 learners were recommended to seek further eye care from an optometrist.

Data were collected from the schools during school hours on predetermined dates between 8 and 16 March 2010. All procedures were performed at the school as all the equipment used was portable and each school provided a testing area on their own premises. The testing area had four different stations, one where the participant's history of complaints potentially associated with vision problems was obtained, and three where visual acuity, amplitude of accommodation and NPC were examined, respectively. Each learner started at the history station where major complaints were noted on the record card, and moved with his/her record card through all the stations.

The visual examinations were performed by the student researchers who had received practical training in these procedures prior to the study. All the examinations were performed according to the methods and procedures described by Kurtz and Carlson ${ }^{7}$. In order to limit the possibility of variable results, each researcher performed the same test throughout the screening. The same questions were asked of all participants during the case history.
Visual acuity (VA) measurements were performed at distance $(6 \mathrm{~m})$ and near $(40 \mathrm{~cm})$ monocular and binocular with a Snellen chart and recorded in Snellen notation as part of the screening process. Visual acuity of $6 / 6$ or better was considered normal for both near and distance testing. If the recorded VA was less than $6 / 12$, the measurement was repeated through a pinhole to determine if the reduced VA was caused by a refractive error or by any underlying pathological condition, in which case VA would not improve. In cases where anterior pathology was evident, learners were advised to seek further eye care from an optometrist. Near point of convergence was measured binocularly to identify learners who did not fall within the norms (break point of $5 \mathrm{~cm}$ and a recovery point of $7 \mathrm{~cm})^{7}$. Amplitude of accommodation was measured monocularly and binocularly using the 'push-up' method ${ }^{7}$.

Each participant's individual aggregate and the grade average for all the children obtained during the most recent school term were obtained from the relevant school. This information was only obtained from teachers after the visual function tests had been completed, in order to avoid bias and ensure objectivity in performing the tests. The current grading system used for Grade 4 to 5 learners consists of four levels and in Table 2, the corresponding percentage range for each level is shown. For the purpose of data analysis, levels 1 and 2 of the grading system were in this study referred to as below average, level 3 as average, and level 4 as above average. 
Table 2. Levels of assessment used for Grade 4-5 learners by the Department of Education.

\begin{tabular}{llcc}
\hline & Level & Percentage range (\%) & Description \\
\hline 1 & S Below average & $\leq 34$ & Not achieved \\
2 & S & $35-49$ & Moderate achievement \\
3 & Average & $50-69$ & Adequate achievement \\
4 & Above average & $70-100$ & Outstanding achievement \\
\hline
\end{tabular}

The results for each independent variable, namely visual acuity, amplitude of accommodation and near point of convergence, were compared to academic achievement to determine whether any associations could be identified.

Statistical analysis of the data was performed by the Department of Biostatistics, University of the Free State. Descriptive statistics, namely frequencies and percentages for categorical data; and medians and percentiles for continuous data, were calculated per academic achievement group (namely below average (Level 1 and 2), average (Level 3) and above average (Level 4)). The three groups were compared by means of $95 \%$ confidence intervals for the percentage difference.

\section{Results}

The median age of participants was 10.3 years, ranging between 8.7 and 12.7 years, and 107 (53.8\%) were female learners. More than half $(54.3 \%)$ of the learners were Sesotho-speaking, while $21.0 \%$ were Afrikaans-, 13.1\% Setswana-, $6.5 \%$ isiXhosa- or 3.0\% English-speaking. The most common complaints potentially indicative of vision problems (headaches $(57.8 \%)$ and eye strain $(58.3 \%))$ of participants are shown in Figure 1.

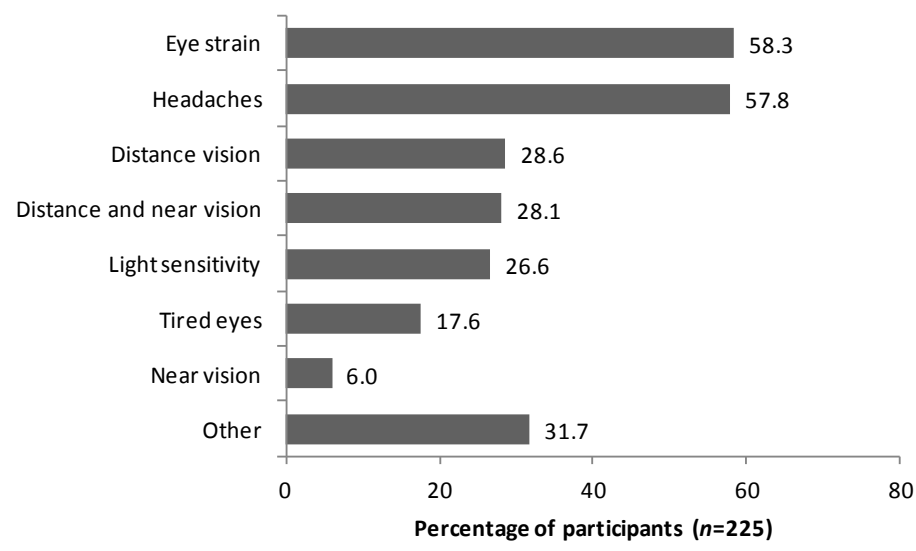

Figure 1. Complaints potentially indicative of vision problems. Complaints listed as other included, for example, ocular itching and redness.
With regard to academic achievement, $18.6 \%$ of the learners were below average (levels 1 and 2 ; $\leq$ $49 \%$ ), 53.8\% were average (level 3; 50-69\%) and $27.6 \%$ were above average (level $4 ; \geq 70 \%$ ).

Distance visual acuities of $6 / 6$ or better were achieved by 167 (83.9\%) of participants, while three $(1.5 \%)$ scored worse than $6 / 12$. For near visual acuity, $153(76.9 \%)$ participants achieved $6 / 6$ or better. Results for near and distance visual acuity are shown in Figure 2. Of all the learners tested, $42.2 \%$ achieved $6 / 6$ or better for both near and distance visual acuity.

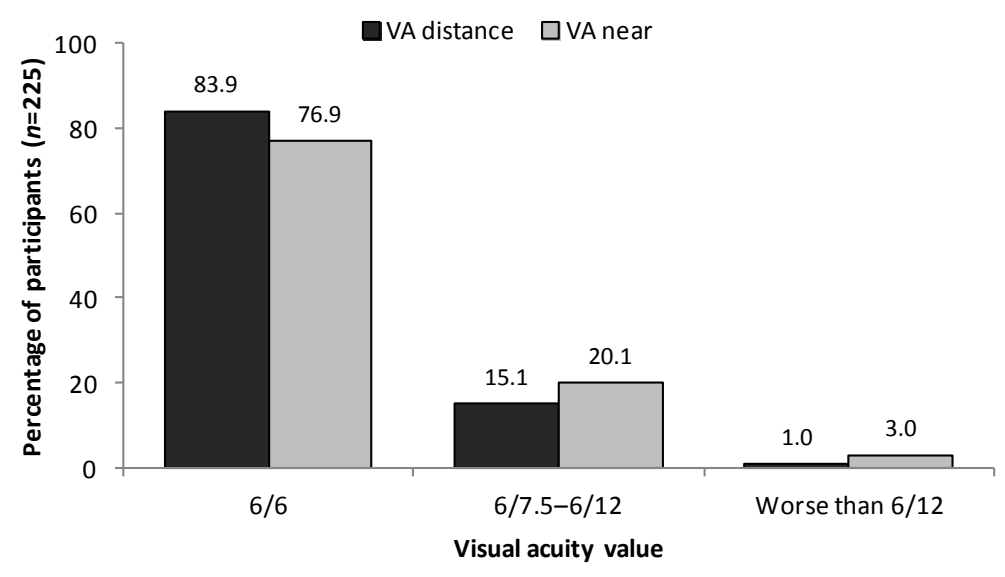

Figure 2. Grade 4 and 5 learners' scores obtained on distance and near visual acuity.

The distribution of participants with less than the minimum required amplitude of accommodation with regard to academic achievement is shown in Table 3. The amplitude of accommodation was found to be less than the minimum requirement in 35 (17.6\%) participants, while in the remainder of participants, amplitude of accommodation was equal to or better than the required minimum. Among those learners with an aggregate below grade average $(n=37), 29.7 \%$ $(n=11)$ did not meet the minimum requirements for amplitude of accommodation. The difference between the samples of below and above average learners $(29.7 \%$ and $12.7 \%$, respectively) with regard to insufficient amplitude of accommodation was found 
to be statistically significant (95\% confidence interval (CI) $[0.4 \% ; 34.3 \%]$ ). However, no statistically significant difference was found between below and average $(95 \%$ CI $[-0.8 \% ; 30.9 \%])$, we do however observe a tendency for below average learners to have less than the minimum amplitude of accommodation (Hofstetter's formula) as compared to learners on par with the grade average.

Table 3: Amplitude of accommodation in association with academic achievement.

\begin{tabular}{lccccc}
\hline & \multicolumn{3}{l}{ Amplitude of accommodation } \\
\cline { 2 - 6 } Academic achievement & $\begin{array}{l}\text { Less than } \\
\text { minimum } \\
\text { required }\end{array}$ & Normal & \\
\cline { 2 - 6 } & $\boldsymbol{n}$ & $\%$ & $\boldsymbol{n}$ & $\%$ \\
\hline Below average $(n=37)$ & 11 & 29.7 & 26 & 70.3 \\
Grade average $(n=107)$ & 17 & 15.9 & 90 & 84.1 \\
Above average $(n=55)$ & 7 & 12.7 & 48 & 87.3 \\
\hline
\end{tabular}

For near point of convergence (NPC), 53 (27.3\%) learners had a receded break point of less than $5 \mathrm{~cm}$, while $162(85.7 \%)$ had a receded recovery point of greater than $7 \mathrm{~cm}$. None of these findings were positively related to academic achievement. Table 4 summarises the association of academic achievement with reduced break point and receded recovery point. According to $95 \%$ CI calculated for differences between the academic achievement groups, none of these differences were statistically significant (Table $5)$.

Table 4: Near point of convergence associated with academic achievement.

\begin{tabular}{lcccc} 
& \multicolumn{3}{c}{ Near point of convergence } \\
\cline { 2 - 4 } $\begin{array}{l}\text { Academic } \\
\text { achievement }\end{array}$ & $\begin{array}{c}\text { Receded } \\
\text { breakpoint } \\
>\mathbf{5} \mathbf{~ c m}\end{array}$ & $\begin{array}{c}\text { Receded recovery } \\
\text { point }>\mathbf{7 m}\end{array}$ \\
\cline { 2 - 5 } & $\begin{array}{c}\text { Number } \\
\text { of learners }\end{array}$ & $\%$ & $\begin{array}{c}\text { Number of } \\
\text { learners }\end{array}$ & $\%$ \\
\hline $\begin{array}{l}\text { Below } \\
\text { average }\end{array}$ & 9 (n=37) & 24.3 & $33(\mathrm{n}=37)$ & 89.2 \\
Grade & & & & \\
average & $33(\mathrm{n}=104)$ & 31.7 & $83(\mathrm{n}=100)$ & 83.0 \\
Above & & & & \\
average & $11(\mathrm{n}=53)$ & 20.8 & $46(\mathrm{n}=52)$ & 88.5 \\
\hline
\end{tabular}

Table 5: Confidence intervals (CI) calculated for the difference in percentages between academic achievement groups.

\begin{tabular}{lll}
\hline & $\begin{array}{l}\text { Receded breakpoint } \\
\mathbf{5} \mathbf{~ c m}\end{array}$ & $\begin{array}{l}\text { Receded recovery } \\
\text { point }>\mathbf{7 m}\end{array}$ \\
\hline $\begin{array}{l}\text { Academic } \\
\text { Achievement }\end{array}$ & $\begin{array}{l}\mathbf{9 5 \%} \text { CI for } \\
\text { difference in } \% \\
\text { (for NPC) }\end{array}$ & $\begin{array}{l}\mathbf{9 5 \%} \text { CI for } \\
\text { difference in \% } \\
\text { (for NPC) }\end{array}$ \\
\hline Below - Average & {$[-21.9 \% ; 10.4 \%]$} & {$[-9.0 \% ; 16.9 \%]$} \\
\hline Below - Above & {$[-13.2 \% ; 21.6 \%]$} & {$[-14.5 \% ; 13.9 \%]$} \\
\hline Average - Above & {$[-4.1 \% ; 23.9 \%]$} & {$[-16.0 \% ; 7.5 \%]$} \\
\hline
\end{tabular}

\section{Discussion and Conclusion}

The only visual function significantly associated with academic achievement, was amplitude of accommodation. Most of the learners had receded break and recovery points with their near points of convergence (NPC); however, these differences were not statistically significant.

Previous international studies of a similar nature reported results in agreement with our findings ${ }^{5,6}$. In total, $43(19.1 \%)$ learners who were found to have visual anomalies or anterior pathology, for example, vernal keratoconjuctivitis, were recommended for further treatment. Our findings emphasise the need for the visual assessment of children prior to the commencement of formal education. Teachers together with parents and/or caregivers should be trained and informed of learners with accommodative and other visual or ocular problems. Parents and caregivers may then be trained on how to perform ongoing visual therapy on these learners.

Future studies of this nature should be conducted in South Africa and elsewhere to determine to what extent other visual functions are associated with academic achievement. Additionally, these studies should incorporate a separation of gender, due to the fact that males and females develop at different rates during early stages of life. A more comprehensive eye examination for learners including ophthalmoscopy and refraction should form part of the investigation. Other disciplines such as occupational therapy, psychology, and speech and hearing therapy could be included to assess various aspects influencing academic achievement in young children.

It is thus evident that the vision screening of child learners is of utmost importance for optimal academic 
performance. Other possible relationships between some visual functions and academic performance are still to be investigated.

\section{Acknowledgements}

To all the learners who willingly participated in the study. Also thanks to Dr. Daleen Struwig, medical writer, Faculty of Health Sciences, University of the Free State, for technical and editorial preparation of the manuscript.

\section{References}

1. Powell C, Wedner S, Richardson S. Vision screening for correctable visual acuity deficits in school-age learner and adolescents. Cochrane Database Syst Rev 200525 CD005023.

2. Metsing TI, Ferreira JT. Visual deficiencies in children from mainstream and learning disabled schools in Johannesburg, South Africa. S Afr Optom 200867 176-184.

3. Moodley VR. Amplitude, facility and accuracy of accommodation in a primary school population. S Afr Optom 2008 67 147-154.

4. Helveston EM, Weber JC, Miller K, Robertson K, Hohberger G, Estes R, Ellis FD, Pick N, Helveston BH. Visual function and academic performance. Am J Ophthalmol 1985 99 346-355.

5. Palomo-Alvarez C, Puell MC. Accommodative function in school learners with reading difficulties. Graefe's Arch Clin Exp Ophthalmol 2008246 1769-1774.

6. Sterner B, Gellerstedt M, Sjöström A. Accommodation and the relationship to subjective symptoms with near work for young school learners. Ophthal Physiol Opt 200626 148155.

7. Kurtz D, Carlson NB. Clinical Procedures for Ocular Examination, $3^{\text {rd }}$ edition. New York: McGraw Hill, 2004. 